\title{
Study on the Update Design Method of Existing Residential Buildings in Northern China Taking Ji'nan as an Example
}

\author{
Xiao Wang ${ }^{1, *}$ Bing $\mathrm{Li}^{2}$ \\ ${ }^{1}$ School of Civil Engineering and Architecture, University of Jinan, Ji'nan, Shandong, China \\ ${ }^{2}$ Tongyuan Design Group Co., Ltd., Ji'nan, Shandong, China \\ *Corresponding author. Email: xiaowang2010@126.com
}

\begin{abstract}
Existing residential renovations have become the main form of urban residential development in Western countries. In China's cities, there are huge housing stocks, the deterioration of living environment and the aging of residential functions. China has taken some measures in this regard. Due to the late start of the research, there are few examples, and the research and implementation of residential regeneration is slightly lagging behind. In order to explore the diversified existing residential regeneration methods, this paper takes the typical residential buildings in Ji'nan as the research object, analyzes the main problems of the existing houses, and selects the typical units of the Wangguanzhuang community to explore the update design method from the residential interior space, the external building envelope structure and the external environment, so as to expand more ideas and methods to enhance the use value of existing residences.
\end{abstract}

Keywords: existing housing, regeneration, design method

\section{INTRODUCTION}

With the rapid development of urban construction in China, by the end of 2014, the urban housing stock was about 20 billion square meters. One half of the housing stocks in northern China were built in the 1980s and 1990s. However, the large-scale construction of residential buildings during this period was low in design standards and poor in construction quality. With the development of the economy, the transformation of the family population and lifestyle, and the continuous improvement of living standards, a large number of residential building functions and environmental quality are increasingly unable to meet people's lives, which seriously lags behind the needs of the times. Taking the typical residential buildings in Ji'nan as an example, this paper analyzes the existing problems of existing houses and discusses the diversified updating methods of existing houses from three aspects: residential interior space, external building envelope structure and external environment.

*Fund: Research on the construction of support system for existing residential diagnosis and restoration. Shandong Natural Science Foundation (ZR2017BEE074)
II. GENERAL SITUATION AND EXISTING PROBLEMS OF EXISTING RESIDENTIAL BUILDINGS IN JI'NAN IN THE 1980S

\section{A. Overview of existing residences in the Ji'nan in the $1980 \mathrm{~s}$}

In the 1980s, the allocation of urban housing in China adopted the method of providing housing for the employees. Therefore, the distribution of living space in Ji'nan residential area is mostly close to the type of occupation. On the edge of the city, residential buildings are used as supporting facilities for industrial enterprises and are attached to industrial areas on the outskirts of the city. There are also old city-renovated communities built in the city center to renovate the original shanty towns. For example, the Wangguanzhuang Community with an area of $491,100 \mathrm{~m}^{2}$ was built in 1988 .

After decades of changes, with the expansion of the city and the population, the urban area of Ji'nan has also increased. The factory and residential areas at the edge of the city at that time are located in the city center or sub-center. The factories move a lot, but the houses remain in the center of the city. The existing large-scale residential areas are located in Lixia District, Licheng District and Huaiyin District. Newly developed residential buildings are smaller in size and scale than 
that in the 1980s, and most of them are far from the city center and are developing east or west. Many residential bases in the 1980s are large in size and occupy important positions in the urban spatial pattern. Compared with these newly developed residential areas, the residential area has superior geographical location, convenient transportation, perfect education, commercial and medical facilities, and has unique advantages.

The main structure of these houses is better overall, and structural safety accidents are relatively rare. In addition, the purpose of the house at the beginning of construction is to resolve the urgent contradiction between supply and demand. Therefore, whether it is the space design inside the house or the construction of the house, it often follows the principle of being economical and practical, and is implemented with reference to the lowest standards. After several decades, this kind of residential houses is far from meeting the needs of the contemporary residents from the apartment type to the use of the area.

\section{B. Existing problem}

1) House type and space: The area is small. Due to the background of the times and the technical level, the indoor living area of the building was generally small. Unreasonable use of functional space due to small real area is also a common phenomenon. For example, due to the small size of the hall, activities such as entertaining guests, family entertainment and even dining are moved to the bedroom; the kitchen is too small, and the refrigerator is placed in the hall or bedroom; there is no storage space, and the balcony is used for stacking items and so on.

Single house type In the 1980s, the difference among the one-bedroom house, two-bedroom house and three-bedroom house was only in the number of rooms. There were only two or three types of houses. In addition, the main space area of all the apartment types, kitchens, bathrooms, etc. is almost the same as the opening and depth.

The use of each functional space is unreasonable. The misalignment of the function occurs mainly due to the small size of each major functional space. Due to the small size of the hall, activities such as entertaining guests, family entertainment and even dining are moved to the bedroom; the kitchen is too small, the refrigerator is placed in the hall or bedroom; there is no storage space, the balcony is used for stacking items and so on.

2) External building envelope structure: The external building envelope structure has poor thermal insulation performance. Due to years of disrepair, the wall is damaged, the roof is leaking seriously, and the external building envelope structure has no insulation and energy saving measures. The outer windows are mostly single-layer wooden windows or steel windows with poor sealing effect, and the building energy consumption is high. In addition, the building auxiliary facilities are obsolete, the pipeline is messy, the lighting and ventilation are poor, the pollution is serious, and the pipeline material is aging. The proportion of installations of solar water heaters is high. However, the solar water heaters are placed in a mess and have serious damage to the roof structure.

3) Outdoor environment: The residential roads have not been re-planned according to the changes in demand and use. The landscape facilities are less, the greening rate is lower, and the plant species are single and relatively monotonous. The parking space is generally lacking in the interior of the community. The motor vehicles are placed disorderly. Due to the lack of public activity space and public service facilities, residents along the street spontaneously develop the ground floor into small shops without necessary beautification and tidiness.

\section{UPDATE DESIGN METHOD OF EXISTING RESIDENTIAL HOUSES}

\section{A. Update design method of internal space}

The internal space update of the old residential buildings mainly includes increasing the area of the built-in or living space, increasing the number of living spaces, and adjusting the space function. The design methods of the transformation mainly include horizontal expansion, dwelling size integration, other adaptive updates, and so on.

1) Horizontal expansion: Part of the building space is expanded in the horizontal direction of the old residential building under the conditions of the residential spacing and the conditions surrounding the residential area. Taking the $7 \#$ and $9 \#$ residential buildings in Wangguanzhuang Community as an example, the residential building was built in 1988, with a three-households, four-storey, united brickconcrete structure residential building. In use, there are many problems such as small living room area, many door openings, large disturbances, a small kitchen and bathroom area, lack of dining space and the corridor pollution. The intermediate household kitchen fume can't be effectively discharged.

The surrounding distance among the buildings is relatively large, and appropriate expansion is carried out in the north direction in order not to affect the sunshine distance and the south-facing lighting needs. The depth increased from $10.5 \mathrm{~m}$ to $13.8 \mathrm{~m}$, and the average building area per household increased from $53.23 \mathrm{~m}^{2}$ to $73.96 \mathrm{~m}^{2}$. After the expansion and 
reconstruction, the layout and the conditions of the kitchen and bathroom have been greatly improved, and the separation of the meals has been achieved. The layout of the unit is regular, the function partition in the building type is reasonable, and the room is convenient and smooth. The plan will transform the original twobedroom and one-hall house into three building types, namely, A-type two-bedroom and two-hall, B-type twobedroom and one-hall and C-type two-bedroom and two-hall (see "Fig. 1").

The changes of each dwelling size are as follows: A type increases the bedroom of $14.64 \mathrm{~m}^{2}$ on the north side, adds the kitchen on the outside of the original kitchen, adds a service balcony outside the kitchen, transforms the original drawing room into a hallway and restaurant, gets through the wall of original southfacing bedroom, and changes the bathroom of living room from the original $0.9 \mathrm{~m}^{2}$ to $1.7 \mathrm{~m}^{2}$. The use area is expanded from $39.42 \mathrm{~m}^{2}$ to $63.31 \mathrm{~m}^{2}$. B type: in order to reduce the impact on the residents, the stairwell is on the north side. No additional construction will be made. It changes the south-bedroom of the C-type to the Btype. The south-side small bedroom is changed to the kitchen. The kitchen increases from $3.46 \mathrm{~m}^{2}$ to $7.53 \mathrm{~m}^{2}$, and the original kitchen is changed to the bathroom, which increases the use area of the bathroom to $3.46 \mathrm{~m}^{2}$. The overall area increases from $37.25 \mathrm{~m}^{2}$ to $50.97 \mathrm{~m}^{2}$. C type adds the drawing room outside the original room on the north side. A $4.5 \mathrm{~m}$-wide bedroom is added to the outside of the stairwell, without affecting the lighting of the original stairwell. A kitchen is added to the outside of the original kitchen, and a service balcony is added to the outside of the kitchen. The usable area is changed from $39.42 \mathrm{~m}^{2}$ to $62.31 \mathrm{~m}^{2}$.

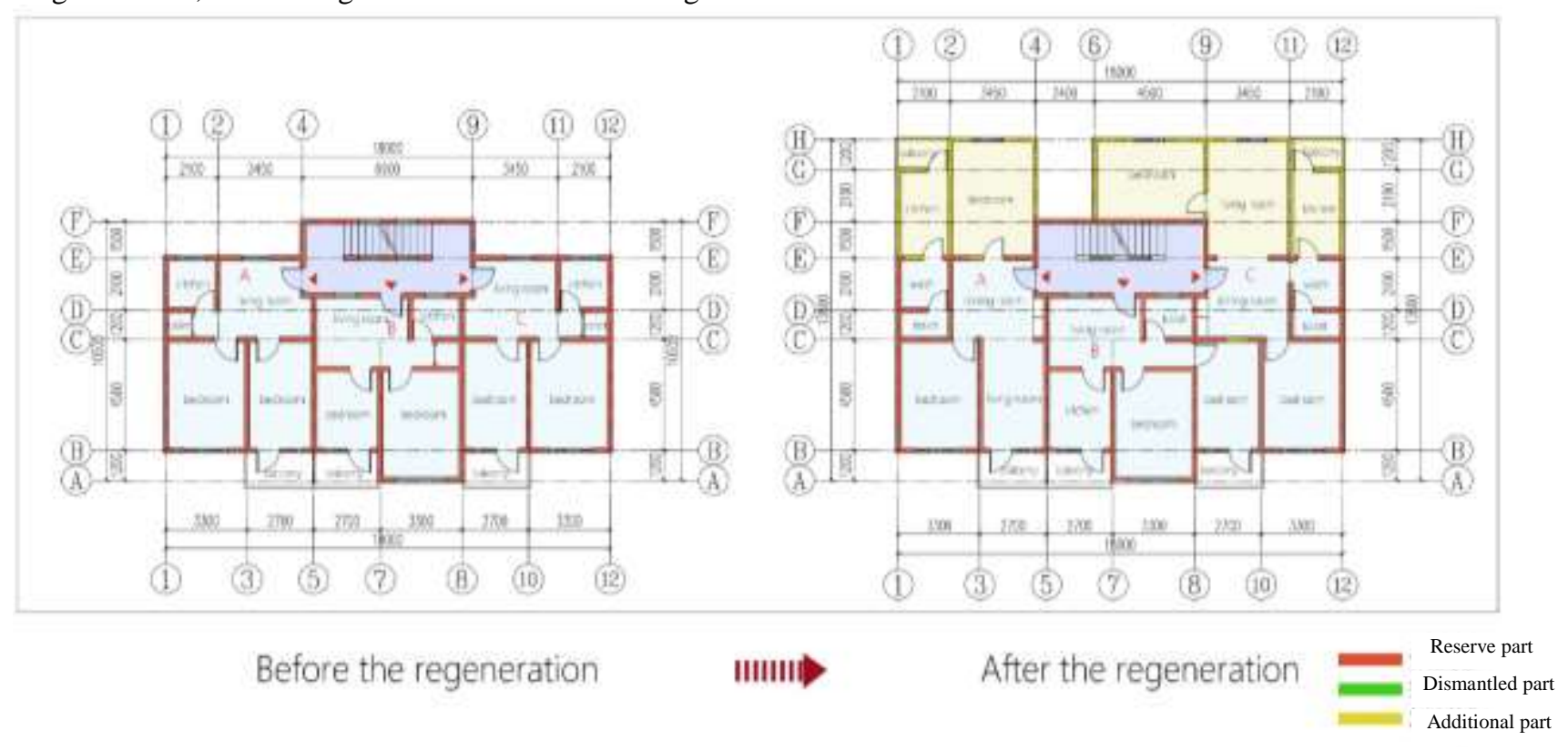

Fig. 1. 7\#, 9\# residential building update schematic.

2) Dwelling size integration: In the $1980 \mathrm{~s}$, the multi-story brick-concrete structure of the old dwellings has a small area and a small number of compartments, and it is difficult to achieve the desired effect. The merging method is an effective way to expand the inside area of the set, increase the number of living spaces, and improve the quality of residential living.

The 21\# building type of Wangguanzhuang Community will be merged and transformed, and the original type of three households with one staircase will be changed into the type of two households with one staircase. The middle C-type household with the worst living environment will be divided into the other two households to re-integrate the plane function. The property right of the intermediate households is bought by the A and B households on both sides. $\mathrm{C}$ household buy other houses or move to the additional houses at the top of the building. In this way, these three households can obtain a larger area of housing with a relatively low investment, improving the living standard of the household.

Before the transformation, the A type is a twobedroom household with a building area of $54.24 \mathrm{~m}^{2}$; the $\mathrm{C}$ type is a two-bedroom household with a building area of $42.3 \mathrm{~m}^{2}$; the $\mathrm{B}$ type is a three-bedroom household with a building area of $71.16 \mathrm{~m}^{2}$. The original kitchen area of this apartment is large enough, the bathroom area is only $1.79 \mathrm{~m}^{2}$, and there is no living room. The addition of the living room and the expansion of the bathroom area are the key points for the renovation. If the household area in the middle is bought by the households on the both sides, the area of 
the living room is increased to $25.49 \mathrm{~m}^{2}$, and the area of the bathroom is increased from $1.79 \mathrm{~m}^{2}$ to $4.34 \mathrm{~m}^{2}$. The north bedroom can also be used as a restaurant. The building area is $79.16 \mathrm{~m}^{2}$, reaching the living standard of the two living rooms and one drawing hall. Type B can increase a room of $17.66 \mathrm{~m}^{2}$ (can be a restaurant), and increase the bathroom area. The total construction area is $92.88 \mathrm{~m}^{2}$, which is the standard of two rooms and one hall. The living conditions of both households have been greatly improved (see "Fig. 2").
The original building of three households with one staircase is changed into a building of one household with one staircase, meeting the needs of multipopulation households. The A-type housing is used as the residential housing for the elderly, and the B-type housing is used as the residential housing for the young people, meeting the needs of the family pension and ensuring the privacy of each other. This increases the selectivity of the house type. The building area has reached $172 \mathrm{~m}^{2} /$ household, and the living conditions have been greatly improved.

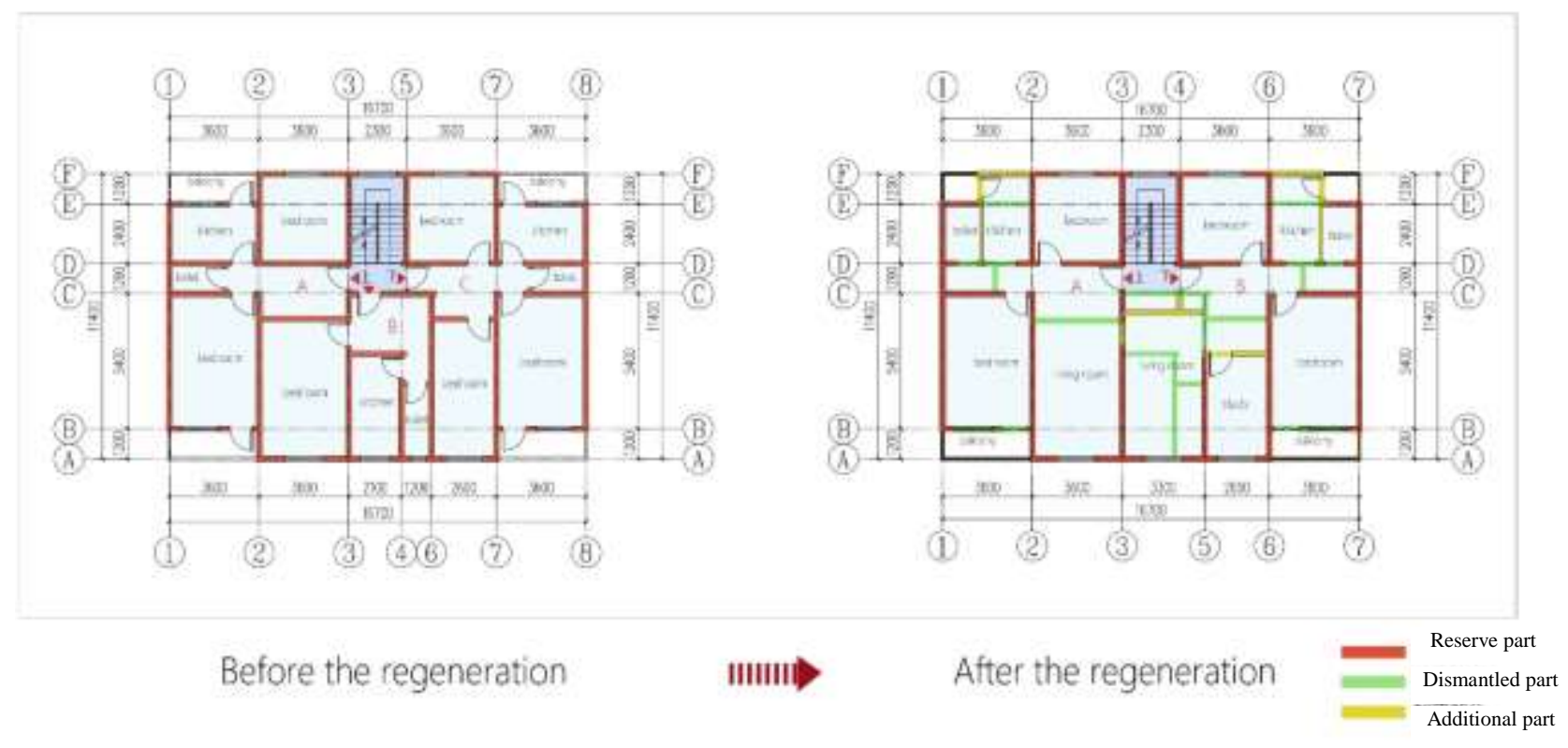

Fig. 2. Schematic diagram of 21 \# floor residential renewal.

3) Other adaptive update: The space of the house, especially the small space, requires versatility. As lifestyles change, the activities within the home will become increasingly complex and specialized, and the addition of rooms and the limited integration equations will make it impossible to provide a space for each function. Therefore, the room must be able to adapt to the diverse needs of the space.

a) Setting up flexible partitions: It can separate the space with a non-bearing wall that can be moved to create different spaces. The setting of the flexible wall should be reasonable. The design should carefully study the local living habits and living needs, and apply the flexible wall to the space that needs the most change. "Fewer but better" is the key point of the flexible wall in residential graphic design. At the same time, the installation is convenient and the structure is firm. By setting a flexible wall, the space can be enlarged or reduced, and the two spaces can be combined into one or one space divided into two. This method is convenient for future transformation and reduces the

waste of resources. However, the main weakness of the flexible wall is that the sound insulation performance is poor, and the product with good performance is difficult to promote in the current stage of renovation due to the high cost of its structure and materials.

b) Creating fuzzy space: A room of a certain area with no predetermined function is designed in the residential plane to replace the functional properties according to different needs in the life process. The location setting of the fuzzy space is very important. The fuzzy space is selected more close to the living room or bedroom. At the same time, the limitation of the area needs to be considered. According to the current situation, the space of $5-8 \mathrm{~m}^{2}$ is suitable. Under the premise of not increasing the area or economic burden, the occupants can fully enjoy the personalized way of living. When it is opened, the area of the adjacent space can be increased; when it is closed, it can be used as a separate space, and its function can be set flexibly according to user needs. In the transformation and building type combination, the corresponding fuzzy space can adopt this method. 


\section{B. Update design method of external building envelope}

1) External form: Based on the lack of technical means, the feasibility of transformation and the consideration of cost, it will carry out simple, small- scale and suitable transformation methods for brickconcrete structures. For the transformation of the external structure of the single building, it is easier to achieve the "addition" of the original building.

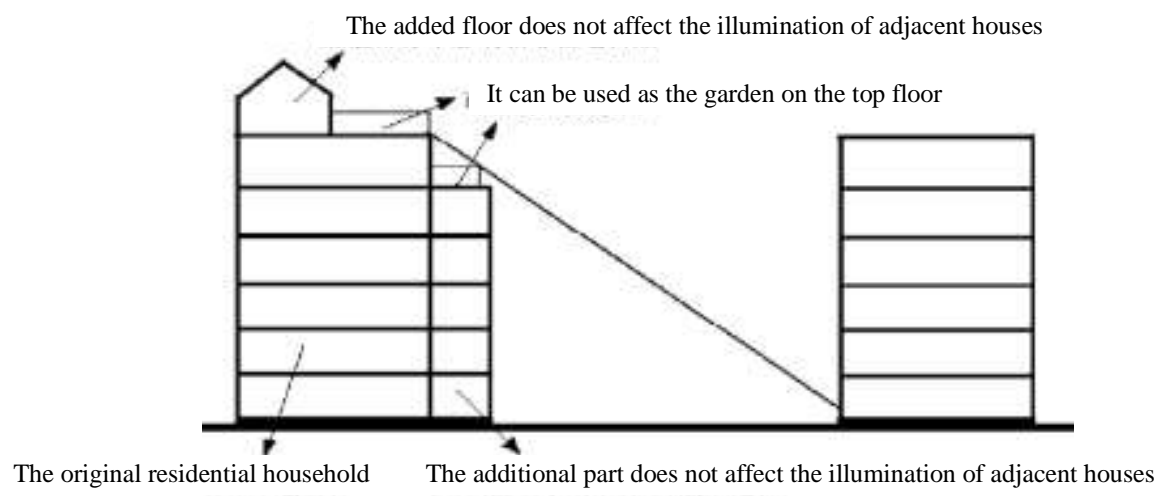

Fig. 3. The schematic diagram of additional separation distance.

a) Buildup standard: A certain amount of sunshine must be achieved in the expansion and reconstruction of the building. The spacing is set on the premise that the rear row of lighting is not blocked. The "Technical Regulations for Urban and Rural Planning Management of Ji'nan City" (for trial implementation) made specific provisions on the spacing between various new construction, expansion and reconstruction of buildings and residential buildings. Among them, the distance between the multi-stories, low-rise buildings with a building height of 24 meters or less and the north-side residential buildings is not less than 1.3 times the relative height of the building in the old city reconstruction area. Adding any facility outside the original designed building should not reduce the original sunshine standard of the adjacent home. The extension should be northward and should not affect normal day lighting in the southward.

b) Adding floors: The building itself has the right conditions to meet the distance of the sunlight, and the room is built on the top floor of the original building. In the case of a constant floor space, it is necessary to increase the living space of the top floor and improve the volume fraction of the old house. The market operation is carried out by increasing the number of households, and the corresponding funds are recovered to subsidize the transformation.

c) Adding a room: For each household, the building area is small, which affects the normal living and use of the households. It is unable to meet minimum living standards. It is necessary to add rooms. The added part shall not block sunlight and affect the original structure of the building as the standard. A new frame structure can be added for additional construction by means of normal construction methods, or it can be modified in combination with the box-type unit method. A new frame structure is added next to the exterior wall of original building, which is used to increase the area and to connect with the original structure. As a new support system, the original building is strengthened and the earthquake resistance level of the building is improved.

\section{2) Exterior wall and roof}

a) Renovation of exterior wall: The building is modeled and calculated for overall insulation design, which maintains the integrity of the building insulation system and prevents the appearance of thermal bridges at various points of contact. On the basis of this, the façade can be modified by various methods such as painting, veneering and grid color block. The facade material of a residential building plays an important role in the aesthetic appearance of the building, especially the color and texture of the material. In the design and transformation, light-colored, bright and large-area blending tones, such as light yellow, light gray, brick red, etc., are interspersed with white tones. It can choose ceramic tile veneer, wooden grille or wooden metal grille on the material to make it easy to get a friendly feeling.

b) The flat roof is changed into a slope: In order to improve the drainage effect of the original flat roof, solve the problems of leakage, heat insulation and heat preservation of the top of the old house, and increase the human landscape of the house, it transforms the flat roof into a traditional sloping roof form. According to the standard of unobstructed rear row house lighting, it should consider the reasonable height and angle of the slope. Ji'nan is located in a cold area, and its optimal arrangement orientation is toward the south. 
Considering the drainage effect of the house and the overall shape of the house, the slope of the roof is finally determined to be $30^{\circ}$. At the same time, the attic transformation is carried out to increase the efficiency of space use. The property rights and use rights after the roof is relocated to the attic are long-term owned by the households. As for the selection of roofing materials: it should repair the original roof with materials with better heat hysteresis, and use roofing materials with low heat transfer and low surface reflection coefficient.

According to the field comparison of the example of the slope change: when the outdoor temperature is 33.9 ${ }^{\circ} \mathrm{C}$ in summer, there is no modified roof, the indoor top surface is up to $32.6{ }^{\circ} \mathrm{C}$, and the air is up to $30.4{ }^{\circ} \mathrm{C}$. After the flat floor is changed into the slope, the maximum temperature of the indoor top surface is 30.6 ${ }^{\circ} \mathrm{C}$, which is reduced by $2.0{ }^{\circ} \mathrm{C}$, while the indoor air is up to $28.6{ }^{\circ} \mathrm{C}$, which is $1.8{ }^{\circ} \mathrm{C}$ lower. According to experts, roof renovation was carried out, and the energy consumption per square meter per year was reduced by about $2.5 \mathrm{kWh}$.

c) Solar energy integration: It can solve the problem of roof leakage and the disorder of solar water heaters combining the roof of the house with a collector. The roof is a suitable place for placing solar collectors. The roof is reserved for water heaters and solar photovoltaic panels. It is installed in a unified manner. It is placed on the slope roof as an architectural element, and the roof is treated to prevent damage to the structure. It should appropriately increase the area of the south slope and increase the area of solar collectors. The solar collectors are installed in rows on the newly added slope roof to make it a decoration of the roof; the water tanks, pipelines, etc. can be hidden inside the slope roof, and the space is better utilized to protect the solar installation from wind and rain. And it is conducive to heat preservation and avoid freezing in winter.

3) Doors and windows: The door and window are the main passages for the exchange of light, heat and wind between the building and the outdoor. Windows with relatively poor thermal insulation reduce the thermal comfort of the room or increase the energy consumption of the room. According to statistics, the heat dissipation of doors and windows accounts for about $2 / 3$ of the heat dissipation on the outer surface of multi-story residential buildings. Under the premise of ensuring the basic functions of the outer window, the winter insulation and summer heat insulation performance are improved to achieve energy saving purposes.

The energy-saving measures for the outer window are mainly from the following aspects: controlling the window-to-wall ratio; improving the thermal insulation performance of the material; increasing the number of layers of the window; improving the airtightness of the window and the shading measures. According to the requirements of the $1980 \mathrm{~s}$, the basic door and window dimensions of each district are consistent with the modular system. The doors and windows with poor thermal insulation and poor sealing performance are uniformly replaced with energy-saving double-glazed windows or single-frame three-glass casement windows, and steel windows and wooden windows are updated to air-tight windows such as aluminum alloy windows and plastic steel windows. At the same time, it is necessary to seal the gap between the door and window. It is possible to close the north-facing open stairwell to reduce heat loss in the winter stairwell and add automatic control doors at the entrance of the unit. In the external thermal insulation transformation, attention should be paid to the sealing measures of the window opening, and the thermal insulation material is extended to the inner side of the window hole to maintain the continuity and integrity of the external thermal insulation.

Ji'nan is in a cold region, but it is also hot in summer. It is known as the one of "four major stoves". Therefore, heat proof is the main thing that should consider in summer, and thermal insulation is the main thing that should consider in winter. The summer sunshade should not block winter sunshine. Due to the high altitude angle of the southward sun in summer, the sunshade can be moved in the form of a grille for the southward opening part such as a balcony or a large opening window, or the sunshade can be adjusted, which is beneficial to the natural ventilation of the building.

\section{Update design method of external environment}

1) Adding new activities and greening sites: It is possible to add and expand the space for residents' outdoor activities, design public space for activities and entertainment venues suitable for the elderly, children and residents, and correspondingly add some sports facilities. Also, it can cooperate with the greening of the old-age center to improve the overall environmental quality.

It is convenient to make greening adjustments on both sides of the road, mainly including street trees, planting shrubs, and creating a green atmosphere. Through the different spatial levels and different viewing period plants, it can form a distinct view of the four seasons. Then, it needs to add street art pieces for artistic treatment. The combination of enclosure, partition, height difference, structure and greening changes the boring of the strip space to form a series of continuous and independent small spaces to meet the needs of various activities. 
2) Renovation of road traffic system: Due to the increase in the number of family vehicles in the residential area, the vehicles parked occupy the green space of the community and the land for the roads, causing traffic congestion and other problems. The roads of some communities will be widened, the road traffic system of the community will be improved, and the road surface renovation and sidewalk paving renovation will be carried out. The increase of special walks for the disabled or the elderly eliminates the obstacles for the elderly during walking. At the same time, it will increase leisure space and landscape essays on the way to provide fun for the elderly. Also, it is possible to increase on-ground parking, air parking and temporary parking. Through the transformation of these methods, it can basically meet the parking demand of the residential area.

3) Improving public facilities: Existing settlements in the 1980s neglected the creation and use of public spaces during the construction. It is necessary to increase the public building facilities and public activities space. At the same time, the establishment of comprehensive leisure places is conducive to the establishment of a sense of community belonging, and is also an important means to promote community integration and harmonious development.

\section{CONCLUSION}

This paper is an exploration of the updated design method for existing houses in Ji'nan City. Existing residential renovations require the government to provide policies, funds, and technical support to promote residential renovation standards and technical standards. It is not a single architectural discipline. It is a multidisciplinary intersection that integrates. For complex factors and challenges, it is necessary to break the traditional architectural thinking mode, integrate contradictions, and require the active participation of residents to effectively reflect the needs of residents.

\section{References}

[1] Real estate market statistics, People's Daily, 2015. (in Chinese)

[2] Ma Mingchun. Study on the living environment in the renewal of old residential areas in Ji'nan City [D]. Jinan: Shandong Jianzhu University, 2011. (in Chinese)

[3] (Japan) Mikan, Residential Recycling Design Manual [M]. Fan Yue, Zhou Bo, trans. Dalian Technology Press, 2009. (in Chinese)

[4] Lv Junhua, China Modern City Residence 1840-2000 [M]. Beijing: Qsinghua University Press, 2003, 8. (in Chinese)

[5] (Japan) Shuichi Matsumura, Settlements Regeneration [M]. Beijing: China Machine Press, 2008, 07. (in Chinese)

[6] Lin Changqing, German Existing Residential Renovation Model and Experience $[\mathrm{J}]$. Construction Science and Technology, 2006, 07. (in Chinese) 